http://jmscr.igmpublication.org/home/ ISSN (e)-2347-176x ISSN (p) 2455-0450 crossref DOI: https://dx.doi.org/10.18535/jmscr/v8i5.46

Journal Of Medical Science And Clinical Research

\title{
Measles outbreak in Gurayat, Saudi Arabia
}

\author{
Authors \\ Mahmoud Abdel Wahed Omar ${ }^{1}$, Eman Abdou Qurany Kassab ${ }^{2}$, \\ Suzan Mohamed Lotfy ${ }^{3}$ \\ ${ }^{1}$ Pediatric Consultant, General Gurayat Hospital, KSA \\ ${ }^{2}$ Lecturer of Pediatric, Pediatrics Department, Faculty of Medicine, Beni Suef University, Egypt \\ ${ }^{3}$ Pediatric Specialist, General Gurayat Hospital, KSA
}

\begin{abstract}
An outbreak of measles had occurred in Gurayat, Saudi Arabia, from July 2018 to April 2019, all suspected cases of measles during measles outbreak was 477 confirmed cases by IgM serology for measles was 286 (60\%) negative cases 191(40\%), confirmed cases in 2018 was 86 (30.1\%), 39 patients were males and 47 patients were females and 200 patients in 2019 was 116 patients were males and 84 patients were females, peak of measles outbreak was in February 2019 their ages ranged from 1 month to 13 years, children aged 2-5 years accounted for the highest number of cases, most of cases presented with fever, cough and rash, $95.5 \%$ of patients non vaccinated.

Among all measles cases 286, only 12 patients (4.2\%) were admitted at pediatric intensive care unit were complicated with sever measles related pneumonia and pneumothorax, among those patients six patients treated with pulse therapy of methylprednisolone $30 \mathrm{mg} / \mathrm{kg} / \mathrm{d}$ for 3 days two of them had Pneumonia with pneumothorax and the others had pneumonia and two of them was connected to mechanical ventilation, after treated with pulse therapy of methylprednisolone their conditions were improved, on the other hand the other six patients didn't treated with pulse therapy of methylprednisolone only one of them improved and the other five patientswere died. patients were successfully treated with intravenous methyl prednisolone as its administration during early severe ARDS is associated with significant improvement in pulmonary and non-pulmonary organ dysfunction.
\end{abstract}

Keywords: Measles, Gurayat, methylprednisolone, pneumonia and pneumothorax.

\section{Introduction}

Measles is a highly contagious viral infection that is transmitted via airborne droplets from the nose, mouth, or throat of an infected individual. The infected person becomes symptomatic 10-14 days after exposure. Initial symptoms include high fever, runny nose, and tiny white spots on the inside of the mouth (Koplik spots). Several days later, a rash develops, starting on the face and upper neck and gradually spreading downwards
(Suter, Buergi et al. 2015; Al-Qayoudhi, AlKindi et al. 2016).

Measles may be transmitted from 4 days before to 4 days after rash onset. Maximum communicability occurs from onset of prodrome through the first 3-4 days of rash (Control, Prevention et al. 2005).

Measles is a highly contagious childhood disease with high morbidity and remarkable mortality (Jahan, Al Saigul et al. 2008). 
Death from measles was reported in approximately $0.2 \%$ of the cases in the United States from 1985 through 1992. With other complications of measles, the risk of death is highest among young children and adults. Pneumonia accounts for about $60 \%$ of deaths, the most common causes of death in children is measles related pneumonia (MRP) (Duke and Mgone 2003; Control, Prevention et al. 2005).

Approximately $30 \%$ of reported measles cases have one or more complications which more common among children younger than 5 years of age and adults 20 years of age and older. The most commonly reported complication of measles otitis media, Pneumonia may be viral or superimposed bacterial, and is the most common cause of measles-related death (Control, Prevention et al. 2005).

In the past few years, several endemic outbreaks of measles have been recognised, not only in children but also in adults, with severe and, occasionally, even fatal complications (Suter, Buergi et al. 2015).

There is no specific treatment for measles, and most people recover within two to three weeks. However, particularly in malnourished and immunocompromised children, measles can cause serious complications, including blindness, encephalitis, croup, severe diarrhea, ear infection, and pneumonia (Al-Qayoudhi, Al-Kindi et al. 2016).

The WHO recommends administration of oncedaily doses of $200,000 \mathrm{IU}$ of vitamin A for two consecutive days to all children aged $\geq 12$ months who have measles (Al-Qayoudhi, Al-Kindi et al. 2016).

Corticosteroids having shown to inhibit measles virus and led to rapid recovery from respiratory distress and normalisation of oxygenation and lung function parameters over time (Suter, Buergi et al. 2015).

Corticosteroids such as IV methyl prednisolone have proven to reduce inflammation in many diseases. Methyl prednisolone induces transcription of many genes which produces anti- inflammatory proteins and switch off genes responsible for activation of inflammatory process (Goldani 2018).

A randomized controlled trial in USA revealed that methyl prednisolone administration during early severe ARDS is associated with significant improvement in pulmonary and nonpulmonary organ dysfunction, which in turn reduces the duration of mechanical ventilation (Zipprich, Winter et al. 2015).

Intravenous immunoglobulins have been effectively used for the post exposure prevention of measles pneumonia When IG is administered to susceptible persons within six days of initial exposure, it may provide protection or modify the clinical course of the disease (Duke and Mgone 2003).

\section{Patients and Methods}

This study was carried out in Gurayat general hospital, which located in the northern borders of kingdom of Saudi Arabia and serving a population of 147,000and based on admitted pediatric patient to Gurayat general hospital with different age group July 2018 to April 2019, cases were collected from infection control department, public health department and pediatric intensive care department, electronic file of each patient was reviewed and recorded in the questioner and data analysis done by using statistical package for social science (SPSS v23) (George and Mallery 2016).

\section{Results}

An outbreak of measles among children had occurred in Gurayat, Saudi Arabia, from July 2018 to April 2019, all suspected cases of measles cases during measles outbreak was 477 confirmed cases by $\operatorname{IgM}$ serology for measles was 286 (60\%), ages ranged between 1 month to 13 years (mean 2.1 year) all cases were Saudis and 54.2\% males and $45.8 \%$ females negative cases 191(40\%) as shown in (table 1) and (figure 1). 
Table (1): Suspected cases of measles

\begin{tabular}{|l|c|c|}
\hline \multicolumn{2}{|l|}{ Suspected cases of measles } & No. (\%) \\
\hline \multirow{2}{*}{ Result $(\mathrm{n}=477)$} & Negative & $191(40)$ \\
\cline { 2 - 3 } & Positive & $286(60)$ \\
\hline
\end{tabular}

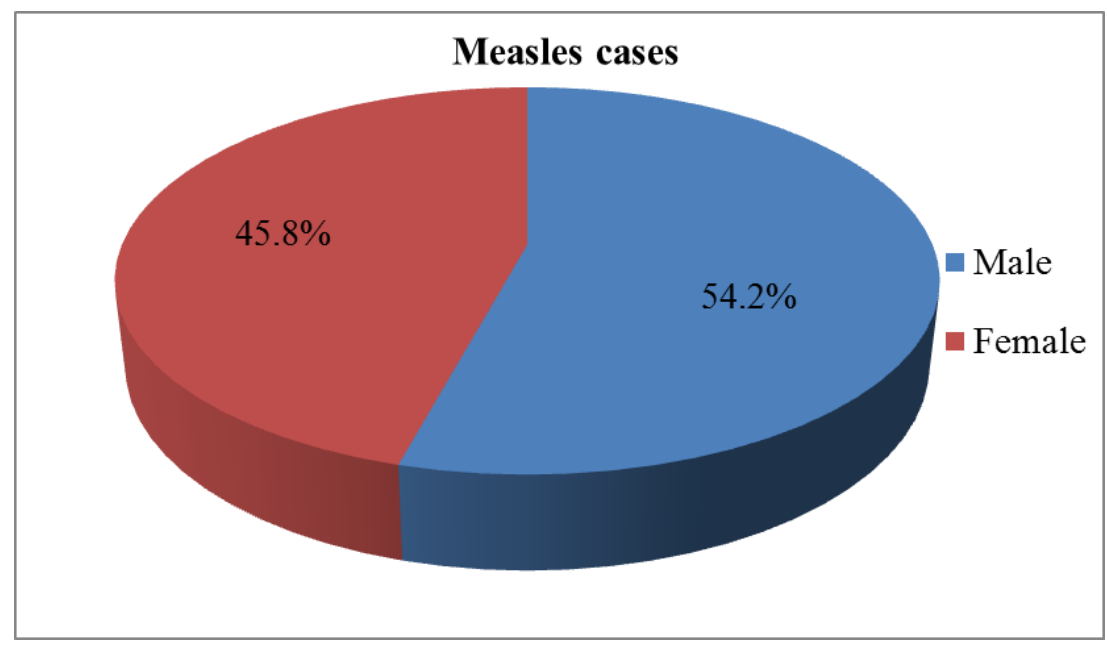

Figure (1): Sex distribution of measles cases

The onset of the outbreak was July 2018, the offset was in April 2019 and the peak was in
February 2019, number of patients was 101 (35.2\%), as shown in (table 2) and (figure 2).

Table (2): Epidemic curve of measles outbreak at Gurayat, Saudi Arabia, from July 2018-April 2019

\begin{tabular}{|l|c|c|c|}
\hline Year & Month & \multicolumn{2}{|c|}{ Measles cases } \\
\cline { 3 - 4 } & & Number & $\%$ \\
\hline \multirow{4}{*}{2018} & July & 12 & 4.2 \\
\cline { 2 - 4 } & August & 4 & 1.4 \\
\cline { 2 - 4 } & September & 6 & 2.1 \\
\cline { 2 - 4 } & October & 23 & 8.0 \\
\cline { 2 - 4 } & November & 25 & 8.7 \\
\cline { 2 - 4 } & December & 16 & 5.6 \\
\hline \multirow{4}{*}{2019} & January & 40 & 14.0 \\
\cline { 2 - 4 } & February & 101 & 35.3 \\
\cline { 2 - 4 } & March & 41 & 14.3 \\
\cline { 2 - 4 } & April & 18 & 6.3 \\
\hline \multicolumn{2}{|c|}{286} \\
\hline \multicolumn{2}{|c|}{ Total } & \multicolumn{2}{|c}{} \\
\hline
\end{tabular}

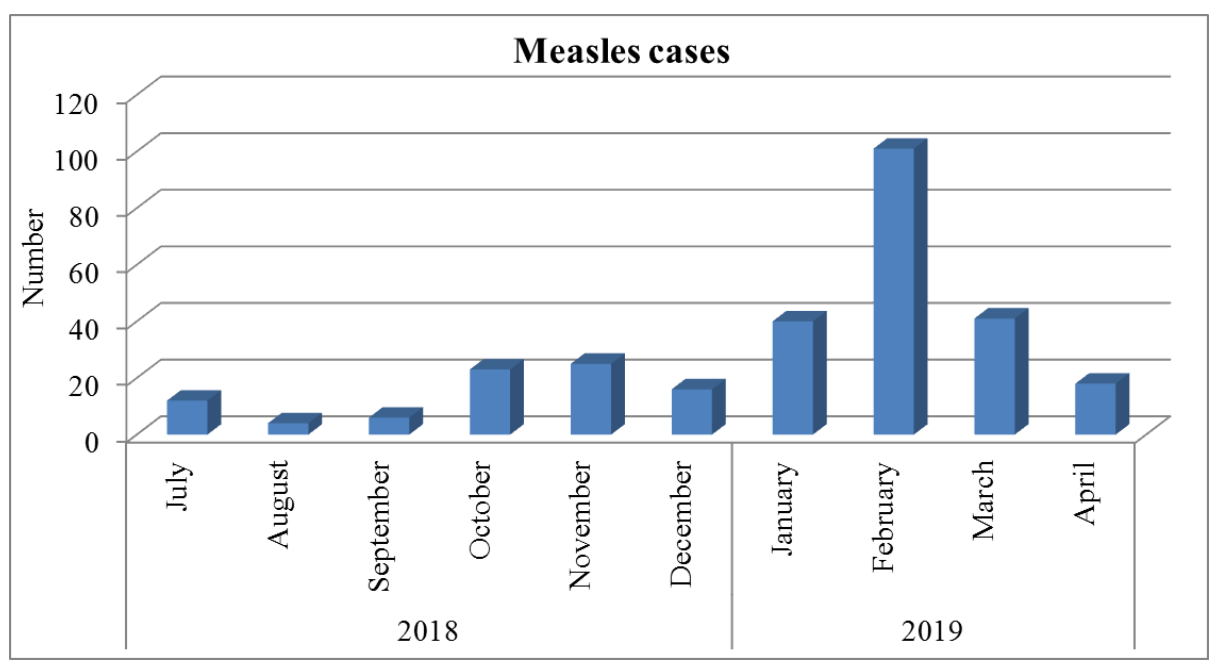

Figure (2): Epidemic curve of measles outbreak at Gurayat, Saudi Arabia from July 2018-April 2019. 
The incidence for lab-confirmed cases was highest for children aged (2-5 year) 83 patients (29\%), followed by age groups (6-11 month) 73 patients $(25.5 \%)$ and (1-2 years) 72 patients $(25.2 \%)$ and the lowest cases for children aged more than 12 year were 2 patients $(0.7 \%)$ as shown in (table 3 ) and (figure 3).

Table (3): Age distribution of measles cases

\begin{tabular}{|l|c|c|}
\hline \multirow{2}{*}{ Age } & \multicolumn{2}{|c|}{ Measles cases } \\
\cline { 2 - 3 } & Number & $\%$ \\
\hline$<6$ month & 40 & 14.0 \\
\hline (6-11) month & 73 & 25.5 \\
\hline (1-2) year & 72 & 25.2 \\
\hline (2-5) year & 83 & 29.0 \\
\hline$(6-12)$ year & 16 & 5.6 \\
\hline (>12) year & 2 & 0.7 \\
\hline Total & \multicolumn{2}{|c|}{286} \\
\hline
\end{tabular}

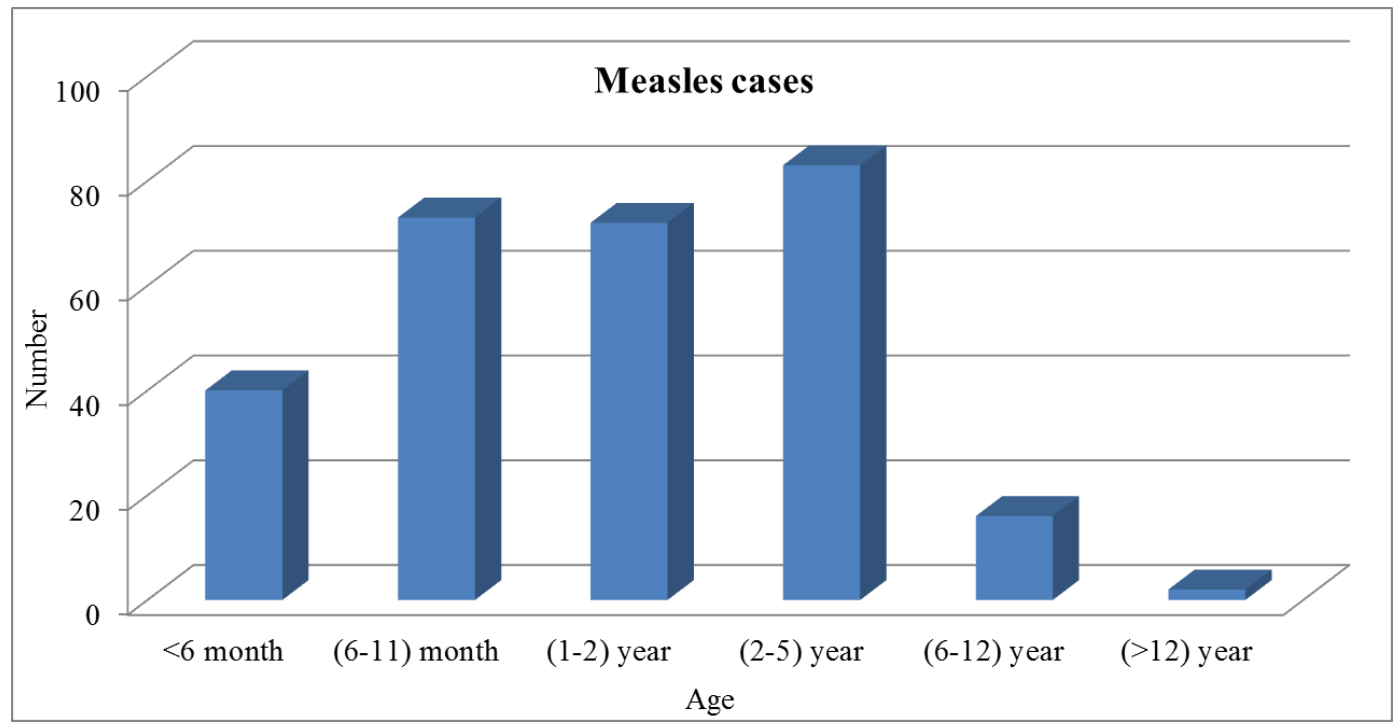

Figure (3): Age distribution of measles cases

Suspected cases for measles in 2018 was 121 and confirmed cases by IgM serology for measles was $86(30.1 \%)$ of all confirmed cases, 39 patients were males and 47 patients were females, while suspected cases for measles in 2019 was 356 and confirmed cases $200(69.9 \%)$ of all confirmed cases, 116 patients were males and 84 patients were females as shown in (table 4 and 5) and (figure 4 and 5).

Table (4): $\operatorname{IgM}$ result for Measles

\begin{tabular}{|l|c|c|c|}
\hline \multirow{2}{*}{ IgM result for Measles } & \multicolumn{2}{|c|}{ Year } & \multirow{2}{*}{ Total } \\
\cline { 2 - 3 } & 2018 & 2019 & \\
\hline Negative & $35(28.9)$ & $156(43.8)$ & 191 \\
\hline Positive & $86(71.1)$ & $200(56.2)$ & 286 \\
\hline Total & 121 & 356 & 477 \\
\hline
\end{tabular}




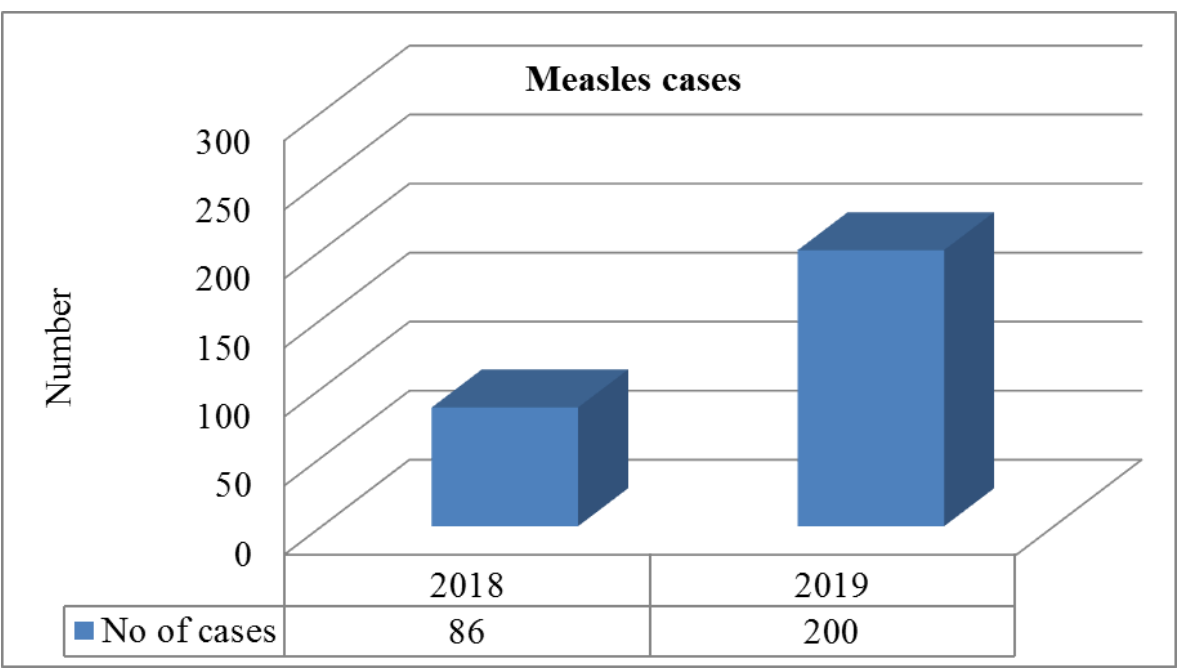

Figure (4): Number of measles cases during the outbreak at Gurayat, Saudi Arabia from July 2018-April 2019

Table (5): Distribution of measles cases according to sex in 2018 and 2019

\begin{tabular}{|l|c|c|c|}
\hline \multirow{2}{*}{ Year } & \multicolumn{2}{|c|}{ Measles cases $(\mathrm{n}=286)$} & \multirow{2}{*}{ Total } \\
\cline { 2 - 3 } & Male & Female & \\
\hline 2018 & 39 & 47 & $86(30.1)$ \\
\hline 2019 & 116 & 84 & $200(69.9)$ \\
\hline Total & $155(54.2)$ & $131(45.8)$ & 286 \\
\hline
\end{tabular}

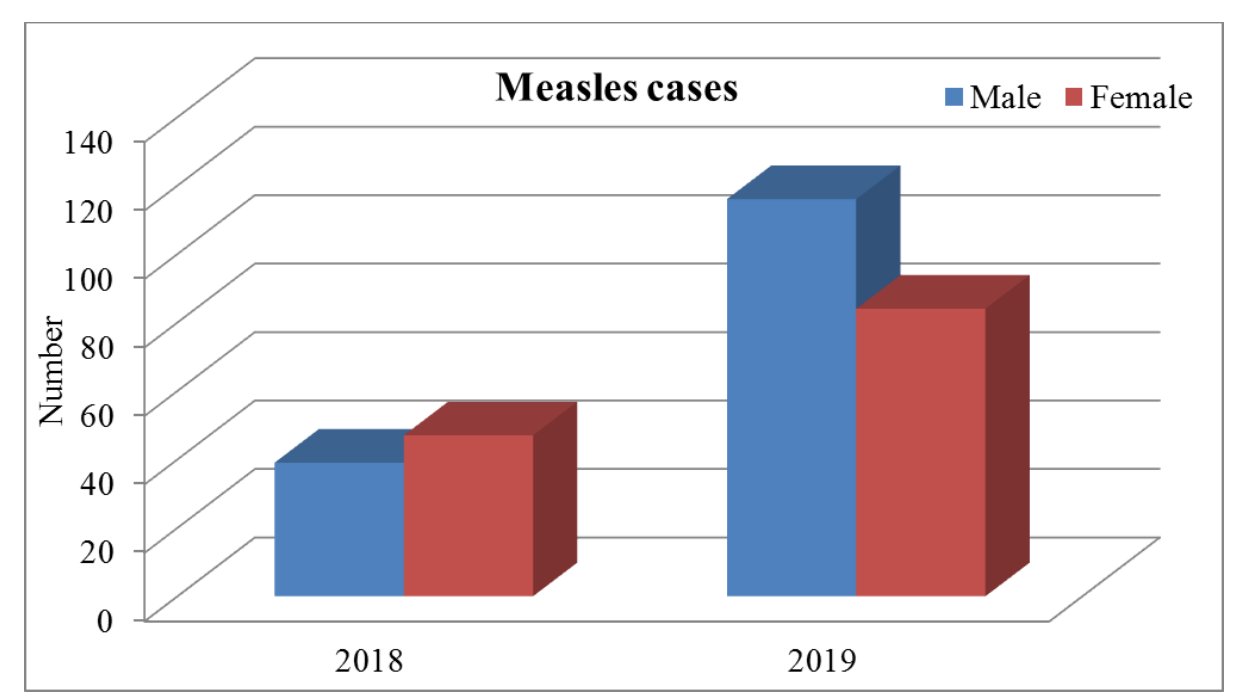

Figure (5): Distribution of measles cases according to sex in 2018 and 2019

All cases (100\%) experienced fever, skin rash and cough, while Coryza $85.3 \%$, sore throat $69.2 \%$, Conjunctivitis $46.2 \%$ and Koplikes spot $1 \%$, most of patients $95.5 \%$ were non-vaccinated, complicated cases pneumonia 65\%,massive bilateral pneumonia $1.4 \%$ and Pneumonia with pneumothorax $1 \%$ as shown in (table 6) and (figure 6). 
Table (6): The properties of measles cases

\begin{tabular}{|l|c|c|c|}
\hline \multicolumn{2}{|c|}{} & \multicolumn{2}{c|}{ Measles cases (n=286) } \\
\cline { 3 - 4 } \multicolumn{2}{|c|}{} & Number & $\%$ \\
\hline \multirow{3}{*}{ Vex } & Male & 155 & 54.2 \\
\cline { 2 - 4 } & Female & 131 & 45.8 \\
\hline \multirow{5}{*}{ Symptoms status } & Vaccinated single dose & 9 & 3.1 \\
\cline { 2 - 4 } & Not vaccinated & 274 & 95.8 \\
\cline { 2 - 4 } & Unknown & 5 & 1.7 \\
\cline { 2 - 4 } & Fever & 286 & 100 \\
\cline { 2 - 4 } & Cough & 286 & 100 \\
\cline { 2 - 4 } & Rash & 286 & 100 \\
\cline { 2 - 4 } & Sore throat & 198 & 69.2 \\
\cline { 2 - 4 } & Coryza & 244 & 85.3 \\
\cline { 2 - 4 } & Conjunctivitis & 132 & 46.2 \\
\cline { 2 - 4 } & Koplik"s spot & 3 & 1 \\
\hline \multirow{3}{*}{ Complication } & Joint pain & 186 & 0 \\
\cline { 2 - 4 } & Pneumonia & 4 & 1.4 \\
\cline { 2 - 4 } & Massive bilateral pneumonia & 3 & 1 \\
\cline { 2 - 4 } & Pneumonia with pneumothorax & & \\
\hline
\end{tabular}

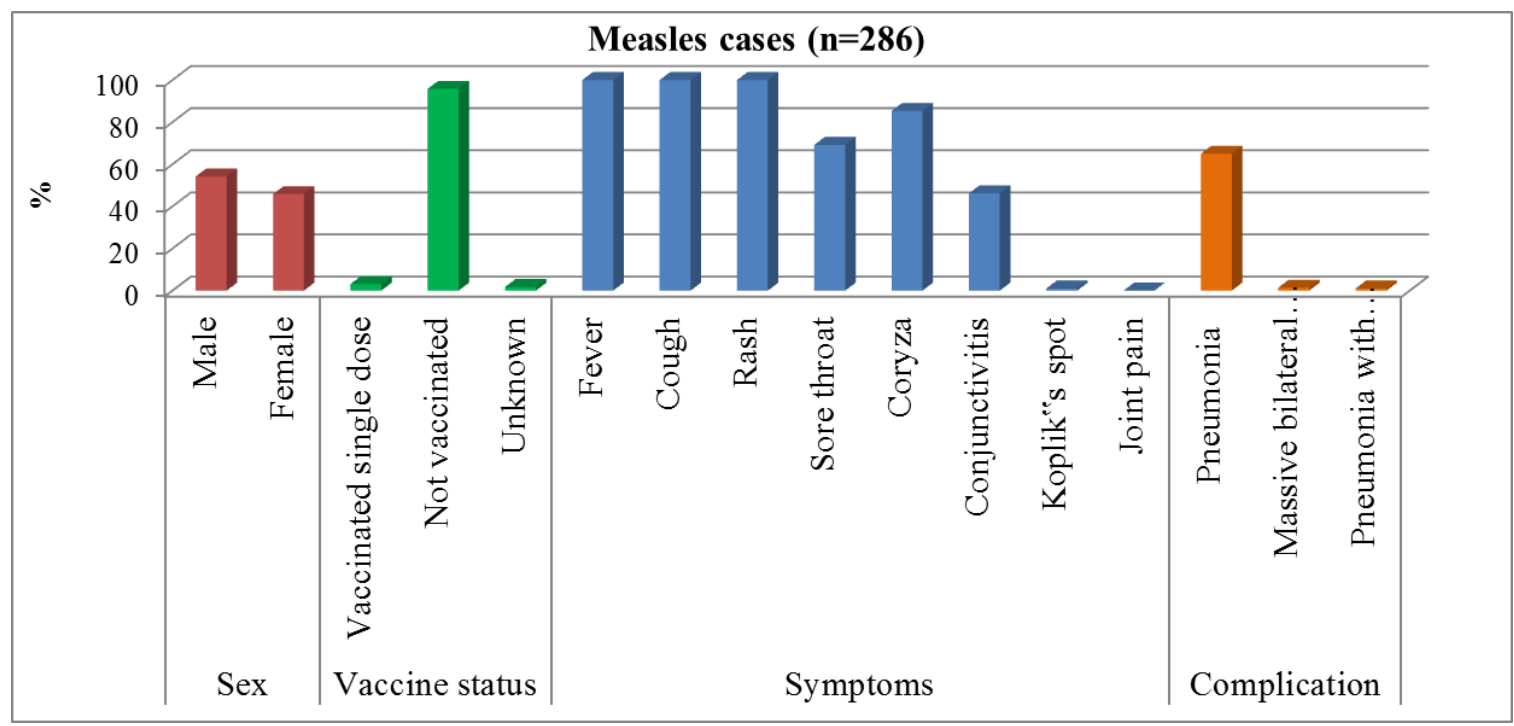

Figure (6): The properties of measlescases

Among all measles cases 286, only 12 patients (4.2\%) were admitted at Pediatric intensive care unit (PICU) were complicated with sever measles related pneumonia and pneumothorax, among those patients 6 patient treated with pulse therapy of methylprednisolone $30 \mathrm{mg} / \mathrm{kg} / \mathrm{d}$ for 3 days (group A), 3 males and 3 females their age ranged between 6 month to 13 month with mean $(\approx 9$ month), two of them had pneumonia with pneumothorax and the others had pneumonia and two of them was connected to mechanical ventilation, after treated with pulse therapy of methylprednisolone their conditions were improved and discharged from PICU to the pediatric ward then discharged to the home.
On the other hand the other sex patients (group B) didn't treated with pulse therapy of methylprednisolone only one of them improved and the other five patient was died, one of them had congenital heart disease and another one had failure to thrive and their age ranged between 5 month to 20 month with mean ( $\approx 11$ month), 4 males and 2 females one of them had Pneumonia with pneumothorax while the other four patients had massive bilateral pneumonia, two of them was connected to mechanical ventilation, comparison between group A; Patient who treated with pulse therapy of methylprednisolone and group B; Patient who didn't treated with pulse therapy of methylprednisolone at PICU in (table 7) and 
(figure 7), there were significant difference between both groups as regarding, complication, associated problem and patients outcome, there was no significant difference between both groups as regarding, sex, age and use of mechanical ventilation.

Table (7): Comparison between group A and B (who admitted at PICU) as regarding the flowing parameters

\begin{tabular}{|c|c|c|c|c|c|}
\hline & & $\begin{array}{c}\text { Group A } \\
\text { No.(\%) }\end{array}$ & $\begin{array}{c}\text { Group B } \\
\text { No.(\%) }\end{array}$ & $P$ value & Sig. \\
\hline \multirow{2}{*}{ Sex } & Male & $3(50)$ & $4(66.7)$ & \multirow{2}{*}{0.575} & \multirow{2}{*}{ NS } \\
\hline & Female & $3(50)$ & $2(33.3)$ & & \\
\hline \multirow{3}{*}{ Age } & $<6$ month & $0(0)$ & $1(16.7)$ & \multirow{3}{*}{0.859} & \multirow{3}{*}{ NS } \\
\hline & (6-11) month & $4(66.7)$ & $2(33.3)$ & & \\
\hline & (1-2) year & $2(33.3)$ & $3(50)$ & & \\
\hline \multirow{3}{*}{ Complication } & Massive bilateral pneumonia & $0(0)$ & $4(66.7)$ & \multirow{3}{*}{0.027} & \multirow{3}{*}{$*$} \\
\hline & Pneumonia with pneumothorax & $2(33.3)$ & $1(16.7)$ & & \\
\hline & Pneumonia & $4(66.7)$ & $1(16.7)$ & & \\
\hline \multirow{2}{*}{$\begin{array}{l}\text { Mechanical } \\
\text { Ventilation }\end{array}$} & No & $4(66.7)$ & $4(66.7)$ & \multirow{2}{*}{1} & \multirow{2}{*}{ NS } \\
\hline & Yes & $2(33.3)$ & $2(33.3)$ & & \\
\hline \multirow{3}{*}{ Associated problem } & No & $6(100)$ & $3(50)$ & \multirow{3}{*}{0.048} & \multirow{3}{*}{$*$} \\
\hline & Congenital heart disease & $0(0)$ & $2(33.3)$ & & \\
\hline & Failure to thrive & $0(0)$ & $1(16.7)$ & & \\
\hline \multirow{2}{*}{ Patients outcome } & Improved & $6(100)$ & $1(16.7)$ & \multirow{2}{*}{0.005} & \multirow{2}{*}{$* *$} \\
\hline & Died & $0(0)$ & $5(83.3)$ & & \\
\hline
\end{tabular}

Group A: Patient who treated with pulse therapy of methylprednisolone

Group B: Patient who didn't treated with pulse therapy of methylprednisolone

$P$ value $>0.05$ (NS) Not significant

$\mathrm{P}$ value $<0.05 *$ Significant at 0.05 level

$\mathrm{P}$ value $<0.01 * *$ Significant at 0.01 Level

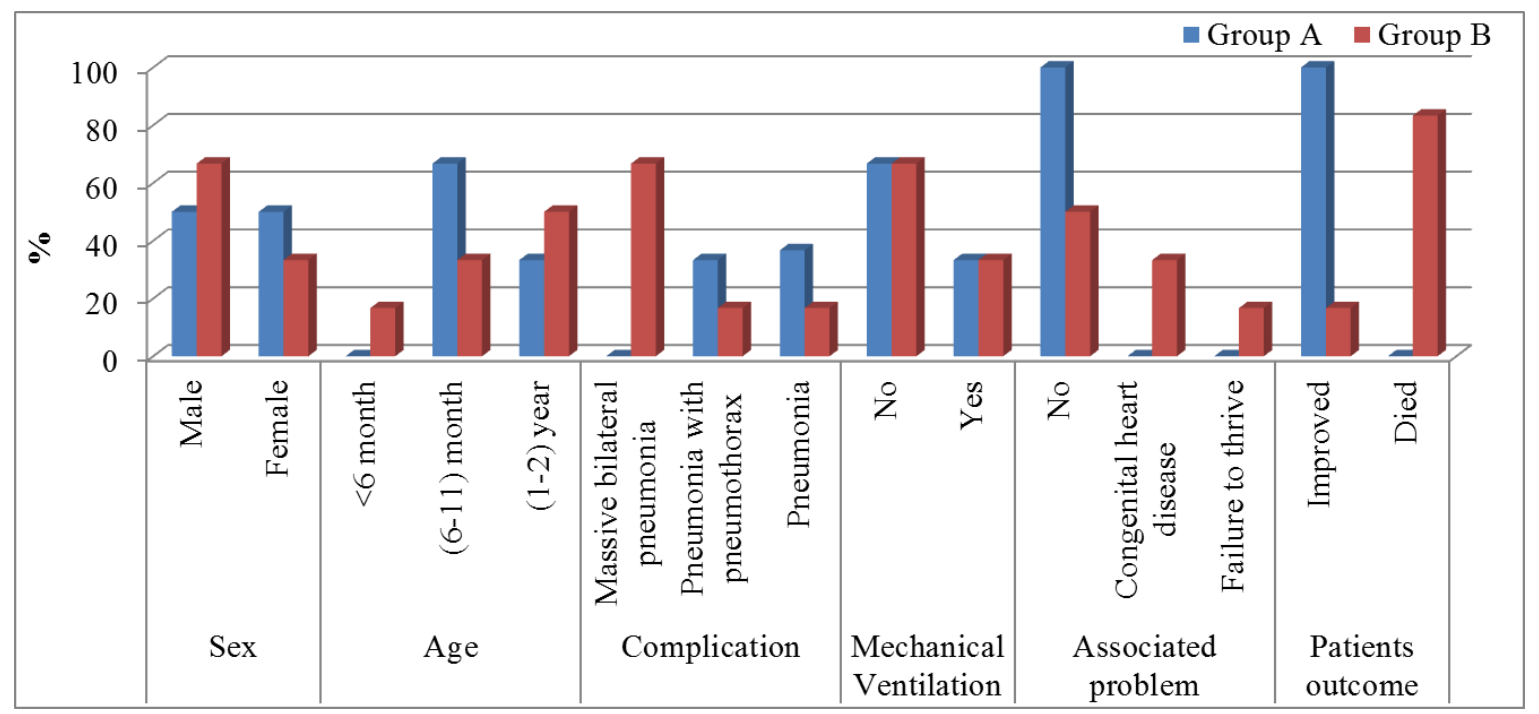

Figure (7): Comparison between group A and B as regarding the flowing parameters

Comparison between patient's outcome at PICU in (table 8) and (figure 8), number of improved PICU patients $7(58.3 \%)$ and 6 of them treated with pulse therapy of methylprednisolone, while 5 $(41.7 \%)$ of PICU patients were died, there were significant difference between both groups as regarding, complication only and no significant difference between both groups as regarding, sex, age, connection to mechanical ventilation and associated problem. 
Table (8): Comparison between patient's outcome (who admitted at PICU) as regarding the flowing parameters

\begin{tabular}{|c|c|c|c|c|c|}
\hline & \multicolumn{2}{|c|}{ Patients } & \multirow[b]{2}{*}{$P$ value } & \multirow[b]{2}{*}{ Sig } \\
\hline & & $\begin{array}{c}\text { Improved }(n=7) \\
\text { No. }(\%)\end{array}$ & $\begin{array}{c}\text { Died }(\mathbf{n}=5) \\
\text { No. }(\%)\end{array}$ & & \\
\hline \multirow{2}{*}{ Sex } & Male & $4(57.1)$ & $3(60)$ & \multirow{2}{*}{0.925} & \multirow{2}{*}{ NS } \\
\hline & Female & $3(42.9)$ & $2(40)$ & & \\
\hline \multirow{3}{*}{ Age } & $<6$ month & $0(0)$ & $1(20)$ & \multirow{3}{*}{0.588} & \multirow{3}{*}{ NS } \\
\hline & (6-11) month & $5(71.4)$ & $1(20)$ & & \\
\hline & $(1-2)$ year & $2(28.6)$ & $3(60)$ & & \\
\hline \multirow{3}{*}{ Complication } & Massive bilateral pneumonia & $0(0)$ & $4(80)$ & \multirow{3}{*}{0.004} & \multirow{3}{*}{$* *$} \\
\hline & Pneumonia with pneumothorax & $2(28.6)$ & $1(20)$ & & \\
\hline & Pneumonia & $5(71.4)$ & $0(0)$ & & \\
\hline \multirow{2}{*}{$\begin{array}{l}\text { Mechanical } \\
\text { Ventilation }\end{array}$} & No & $5(71.4)$ & $3(60)$ & \multirow{2}{*}{0.692} & \multirow{2}{*}{ NS } \\
\hline & Yes & $2(28.6)$ & $2(40)$ & & \\
\hline \multirow{3}{*}{$\begin{array}{l}\text { Associated } \\
\text { problem }\end{array}$} & No & $6(85.7)$ & $3(60)$ & \multirow{3}{*}{0.432} & \multirow{3}{*}{ NS } \\
\hline & Congenital heart disease & $1(14.3)$ & $1(20)$ & & \\
\hline & Failure to thrive & $0(0)$ & $1(20)$ & & \\
\hline
\end{tabular}

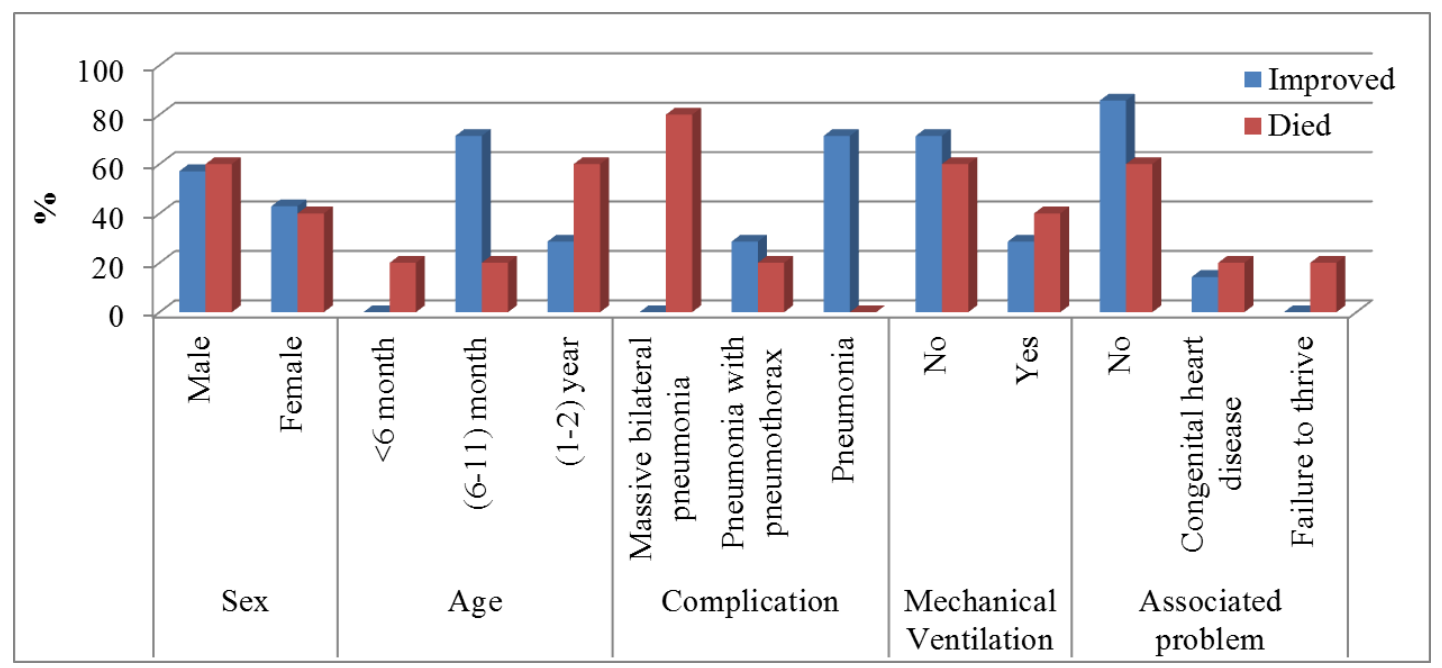

Figure (8): Comparison between patient's outcome (who admitted at PICU) as regarding the flowing parameter

\section{Discussions and Conclusions}

Measles is one of the leading causes of death among young children all case who died during measles outbreak less than 2 years, The study concludes that the most common age group affected during this outbreak is 2-5 years, more in males than females, the measles outbreak at Gurayat occurred due to lack of vaccination as $95.5 \%$ of patients were non-vaccinated so to prevent future outbreaks we should encourage the people to follow the instruction of the immunization programs and vaccinate their children to protect them from infectious diseases.

Comparing treatment responses in two groups of patients with measles who admitted at PICU, group A received methylprednisolone group B was managed with supportive measures and didn't received methylprednisolone. Patients who received methylprednisolone showed $100 \%$ recovery compared to $17 \%$ of patients managed with supportive measures and didn't received methylprednisolone and death in this group was $83 \%$, our patients showed an excellent response to steroid therapy with full recovery within two weeks, so the use of steroids should be considered in management of complicated cases of measles.

Public health departments helped in the diagnosis of measles, trace contacts, and offer post-exposure prophylaxis by prevention through vaccination with two doses measles vaccine, at least 28 days 
apart, with the first dose given at 12 months of age or older, If a patient exposed to measles, without presumptive immunity to measles and is > 6 months old, vaccinate with MMR within 72 hours of exposure to prevent or modify measles severity also vaccination of health care workers and pregnant women should not receive the vaccine.

\section{Recommendation}

Increase the awareness of population to the importance of vaccination programs, good ventilation, aeration and personal hygiene in prevention of infectious diseases through the Public health departments. The use of steroids should be considered in management of complicated cases of measles.

\section{References}

1. Al-Qayoudhi, A., H. Al-Kindi, et al. (2016). "Acute measles encephalitis in an immigrant syrian child: case report and review of the literature." Oman medical journal 31(2): 150.

2. Control, C. f. D., Prevention, et al. (2005). Epidemiology and prevention of vaccine-preventable diseases, Department of Health \& Human Services, Public Health Service, Centers for ....

3. Duke, T. and C. S. Mgone (2003). "Measles: not just another viral exanthem." The Lancet 361(9359): 763773.

4. George, D. and P. Mallery (2016). IBM SPSS statistics 23 step by step: A simple guide and reference, Routledge.

5. Goldani, L. Z. (2018). "Measles outbreak in Brazil, 2018." Brazilian Journal of Infectious Diseases 22(5): 359-359.

6. Jahan, S., A. M. Al Saigul, et al. (2008). "Measles outbreak in Qassim, Saudi Arabia 2007: epidemiology and evaluation of outbreak response." Journal of public health 30(4): 384-390.
7. Suter, C., U. Buergi, et al. (2015). "Severe acute measles pneumonitis: virus isolation in bronchoalveolar lavage fluid." Case Reports 2015: bcr2015210826.

8. Zipprich, J., K. Winter, et al. (2015). "Measles outbreak - California, December 2014-February 2015." MMWR. Morbidity and mortality weekly report 64(6): 153. 